\title{
Everything you always wanted to know about Rabies Virus (but were afraid to ask)
}

\author{
Benjamin M. Davis ${ }^{1}$, Glenn F. Rall ${ }^{2}$, Matthias J. Schnell ${ }^{1,2,3,}{ }^{*}$ \\ ${ }^{1}$ Department of Microbiology and Immunology, Sidney Kimmel Medical College, Thomas \\ Jefferson University, Philadelphia, PA, USA \\ ${ }^{2}$ Fox Chase Cancer Center, Philadelphia, PA, US \\ 3Jefferson Vaccine Center, Sidney Kimmel Medical College, Thomas Jefferson University, \\ Philadelphia, PA, USA
}

\section{Abstract}

The cultural impact of rabies, the fatal neurological disease caused by infection with rabies virus, registers throughout recorded history (1-3). Although rabies has been the subject of large-scale public health interventions, chiefly through vaccination efforts, the disease continues to take the lives of about 40,000-70,000 people per year, roughly $40 \%$ of whom are children $(4,5)$. Most of these deaths occur in resource-poor countries, where lack of infrastructure prevents timely reporting and post-exposure prophylaxis, and the ubiquity of domestic and wild animal hosts makes eradication unlikely. Moreover, while the disease is more rare than other human infections such as influenza virus, the prognosis following a bite from a rabid animal is poor: there is currently no effective treatment that will save the life of a symptomatic rabies patient. This review focuses on the major unanswered research questions related to rabies virus (RABV) pathogenesis, especially those connecting the disease progression of rabies with the complex dysfunction caused by the virus in infected cells. The recent applications of cutting-edge research strategies to this question will be described in detail.

\section{Keywords}

rabies virus; lyssaviruses; neurotropic virus; neuroinvasive virus; viral transport

\section{1) Rabies virus taxonomy, structure, and life cycle within the infected cell}

The causative agent of rabies, RABV, is negative-stranded RNA virus of the genus Lyssavirus (Greek: Lyssa, goddess of rage or madness) (2). RABV is a member of the Rhabdoviridae family (Greek: rhabdos, rod), named for the characteristic rod- or bulletshaped rhabdovirus virion observed by electron microscopy (6). Rhabdovirus virions, like other negative-stranded RNA viruses, are comprised of a highly stable and organized

\footnotetext{
*Corresponding Author. Mailing address: Department of Microbiology and Immunology, Thomas Jefferson University, 233 South 10th St., 531 BLSB, Philadelphia, PA 19107.Phone: (215) 503-4634. Fax: (215) 503-5393. Matthias.Schnell@ jefferson.edu.
} 
complex of genomic RNA and nucleoprotein, contained in a lipid envelope derived from the host cell membrane (7).

RABV is the most prominent member of the lyssavirus genus, with a global distribution and long history of study. However, there are several other lyssaviruses that can also cause fatal rabies-like disease. Fourteen rabies-related lyssaviruses are currently known, including Mokola Virus, European Bat Lyssavirus 1 and 2, and Australian Bat Lyssavirus (2). These lyssaviruses tend to be geographically restricted and cause a minority of human rabies fatalities, but may emerge more prominently as humans encroach on new areas and habitats in which these viruses are endemic. Most of our current knowledge of these viruses has come from ecological studies of bats, but recently several teams have used experimental virology techniques to learn more about lyssavirus diversity (8-11).

All rhabdoviruses encode five structural proteins: nucleoprotein $(\mathrm{N})$, phosphoprotein $(\mathrm{P})$, matrix protein (M), glycoprotein (G), and an RNA-directed RNA polymerase (L) (Figure 1A) (7). The N protein encapsulates the RNA genome, forming a tightly wound N-RNA complex known as a ribonucleoprotein (RNP) $(12,13)$. The RNP is condensed, along with $\mathrm{L}$ and $\mathrm{P}$, into a helical nucleocapsid (NC) (12). The P protein is a non-catalytic co-factor for the polymerase $\mathrm{L}$. The $\mathrm{M}$ protein surrounds the $\mathrm{NC}$, forming a bridge between the $\mathrm{NC}$ and the viral envelope $(14,15)$. The trimeric $\mathrm{G}$ protein, which interacts at its cytoplasmic side with matrix protein, is the only protein exposed on the surface of the rhabdovirus envelope (16), and is the sole ligand for the cellular receptor. Many rhabdoviruses express additional proteins of diverse function; the RABV genome consists only of these five (17). The contributions that each of the individual RABV proteins make to RABV pathogenesis go far beyond their structural functions, and will be discussed throughout this review. For instance, RABV-P has functions other than serving as polymerase cofactor, such as the disruption of host interferon-mediated antiviral defense (18).

A generalized life cycle is observed across the rhabdovirus family (illustrated by Figure 1B) (7). The virus $G$ protein interacts with host cellular receptors, triggering endocytosis of the virion $(19,20)$. The lower $\mathrm{pH}$ of the endosome catalyzes a $\mathrm{G}$ protein-mediated fusion between the viral envelope and the endosomal membrane, releasing the $\mathrm{NC}$ into the cytoplasm (20). The functional viral polymerase, which is a complex of $\mathrm{L}$ and $\mathrm{P}$, uses the released RNP as a template for repetitive rounds of transcription (21). The expression levels of rhabdovirus mRNAs, and therefore the proteins they encode, are maximal at the 3' end of the genome and become sequentially less abundant toward the 5' end of the genome (Figure 1C). Thus, the $\mathrm{N}$ protein is most abundant, followed by $\mathrm{P}, \mathrm{M}, \mathrm{G}$, and $\mathrm{L}$. This decrement is due to disassociation of the polymerase from the RNP during transcription when a termination signal is reached, requiring the polymerase to re-engage to initiate transcription of the downstream gene $(22,23)$. Viral replication starts once a certain threshold of viral $\mathrm{N}$ protein has been produced, and, for RABV, this is thought to be regulated by M protein levels $(24,25)$. For replication, the viral polymerase switches to a more processive mode, producing a full-length, positive-sense RNA antigenome $(25,26)$. This intermediate then serves as the template for the production of full-length negative sense genomes. Finally, the rhabdovirus budding mechanism begins with the insertion of $\mathrm{G}$ protein into the host cell 
membrane $(27,28)$. The $\mathrm{M}$ protein of the nascent $\mathrm{NC}$ interacts with the cytoplasmic tail of $\mathrm{G}$, triggering budding of the virus from the host-cell membrane $(15,28)$.

Despite close similarities in morphology and life cycle, different members of the rhabdovirus family have a wide array of species host range and in vivo phenotypes. For instance, the best-studied rhabdovirus besides RABV, vesicular stomatitis virus (VSV), is a pathogen of cattle that does not cause severe human disease. RABV, with its narrow cellular tropism, absence of cytopathic effect, and long incubation can be contrasted with VSV's broad cellular tropism, cytotoxic life cycle, and fast replication $(5,29,30)$. RABV has tropism for mammals; other rhabdoviruses infect fish, insects, and plants (17).

\section{2) The journey of RABV infection through the host: Overview}

Most human RABV exposures are a result of animal bites or scratches, which expose muscle tissue to animal saliva containing RABV particles (Figure 2) (31). One of the known receptors of RABV, the nicotinic acetylcholine receptor (nAchR), is restricted to muscle cells, evidence for primary infections of muscle cells followed by transmission to neurons (Figure 3) (31). In the current model of RABV neuroinvasion, the RABV particles enter the CNS by budding from muscle cells into the synaptic cleft of neuromuscular junctions (NMJs), the specialized synapses between efferent nerve terminals and muscle fibers. It is thought that RABV entry into primary motor neurons is followed by retrograde axonal transport, replication and assembly in the neuronal cell body, and then transport to and budding from another synapse to start a new round of infection and resultant neuron-toneuron spread. In this model, the process of trans-synaptic spread continues until RABV is widely distributed in the CNS (Figure 2). This causes behavioral changes that support the spread of the virus to a new host. Simultaneously, RABV undergoes a "centrifugal" spread from the CNS into several extraneural organs, including (among others), the skin, hair follicles, heart, adrenal glands, tounge, and the salivary gland (32-35).

Viral CNS invasion is not unique to RABV, but several characteristics set RABV apart from other neuroinvasive viruses. During early stages of infection, RABV penetrates and is transported exclusively by primary motor neurons, rather than sensory and autonomic neurons such as in the case of neuroinvasive alpha-herpesviruses $(32,36)$. Once in the CNS, RABV displays 1) strict preference for neurons rather than other CNS cells such as microglia and astrocytes, 2) exclusive trans-synaptic spread of virus without release at other parts of the neuron, and 3) lack of histopathological evidence of damage to infected tissue (32). Despite these being reliably observed features of RABV infections, the ways in which RABV biology determines these properties are not well understood.

The lack of apparent damage to neurons is especially compelling to current researchers. How does RABV infection kill the host without inducing widespread neuronal death? Unraveling this question at the molecular level is a major challenge in the field of RABV virology, and perhaps key to understanding rhabdoviral pathogenesis, design of improved treatments, and insights into neuronal biology. Investigations of the morphological, potentially inflammatory, and genetic changes in infected cells is the subject of much ongoing study, and will be discussed at the end of this review. 


\section{3) Experimental use of rabies virus}

When addressing RABV pathogenicity experimentally, it is important to first consider the diversity of RABV strains available to researchers. Different strains may produce conflicting results, even in the same system. RABV strains can be categorized a number of ways, including by passage history (laboratory adapted or wild-type isolate), animal source, and pathogenicity (none, conditional, high). These are discussed briefly below.

Laboratory-adapted "fixed" strains of RABV are those viruses that have a long passage history in tissue culture or animals. These have the advantage of well-defined incubation periods and a predictable clinical course in experimental models. However, fixed strains may have lost properties of their wild-type ancestors, such as local replication in muscle prior to CNS invasion. Fixed RABV is not necessarily apathogenic; for example, the pathogenic CVS strain (for Challenge Virus Standard) is commonly used for post-vaccination challenge studies, where a pathogenic virus is required (37).

The animal source of wild-type isolates, such as bat-associated or dog-associated, may also be predictive of the virus' phenotype. For instance, it has been suggested that bat-associated virus can initiate CNS invasion following relatively minor bite wounds, while dog-associated strains require deep penetration into muscle to do the same (38-40). This difference in infectivity may reflect an increased ability of bat-associated viruses to infect and replicate in epithelial or subcutaneous tissue, but the mechanism underlying this observation is not well understood (40).

Finally, the availability of pathogenic and apathogenic (attenuated) sub-strains of similar viruses allows investigators to study the contribution made by individual RABV genetic elements to pathogenicity. This has been a productive line of research in the years since molecular cloning of RABV became possible (41). In these studies, researchers generated chimeric RABVs exchanging genes or parts of genes between more or less pathogenic counterparts and characterized the differences in pathogenicity $(5,41)$. Several of these studies are discussed throughout this review.

Another important distinction among rabies research strategies is the use of peripheral or CNS inoculation sites. Direct infection of the CNS is usually accomplished by intranasal or intracranial inoculation. These strategies conceptually separate RABV CNS replication and spread from the peripheral neuroinvasive mechanism necessary for most natural infections. For the most part, however, neuroinvasion, neurotropism, and neuropathogenicity of rabies viruses are correlated in vivo (38). Models of natural RABV infections usually use intramuscular inoculation of laboratory animals.

\section{4) Neuroinvasion: Penetration of the CNS}

From a peripheral site of exposure, neurotropic pathogens such as RABV must enter the CNS to spread and cause disease. However, the mammalian CNS has several anatomical and biochemical barriers which separate it from the rest of the body. Among the most widely studied natural defense barrier is the blood-brain barrier (BBB), the highly selective permeability barrier of the neurovascular epithelium, made of up tight junctions between the 
epithelial cells. In addition to the BBB, the CNS' lack of lymphatic drainage, low MHC expression, and elevated levels of immuosuppressive molecules collectively contribute to a state of immunological isolation relative to the rest of the body (42). This concept, once referred to as "immune privilege" has been revised, as immune responses can and do occur within the CNS, and thus, technically, the brain is not "privileged". Rather, the nature of the immune response-from the signals that induce it to the processes that govern the antiviral response in the CNS - are fundamentally distinct from those that have been defined in peripheral organs.

There are several mechanisms by which a virus can overcome barriers that limit neuroinvasion. Retrograde transport along axons from the periphery, the primary mechanism of $\mathrm{RABV}$ neuroinvasion, is also a route of infection for alphaherpesviruses and possibly others (43-45), allowing viral infections to bypass the BBB which would limit hematogenous entry. A related mechanism of viral neuroinvasion is through olfactory receptors, which are the only CNS cells directly exposed to exterior environment and are therefore likely gateways to CNS infections (46). Intranasal infections are widely used in research, but aside from the possibility of airborne virus in bat-infested caves, sufficiently dense aerosols of neuroinvasive viruses are not encountered in nature (46). Finally, the most common mechanism for viral CNS entry is a hematogenous route, where viral particles penetrate the BBB by infecting the neurovascular epithelium or a CNS-infiltrating lymphocyte or monocyte. CNS complications of flavivirus or paramyxomvirus infections are thought to occur primarily through this route $(42,46)$. While hematogenous spread of RABV from the periphery to the brain has been demonstrated in the laboratory for silver haired bat RABV (SHBRV), it is not thought to be a major contributor to natural RABV infections and was not observed for a dog-derived RABV (47).

In natural infections, RABV neuroinvasion takes place at neuromuscular junction (NMJ). The strongest early evidence for this came when a protein-protein interaction between RABV and the nicotinic acetylcholine receptor (nAchR) was discovered, making the $\mathrm{nAchR}$ the first known RABV cellular receptor (CNS-restricted receptors would be discovered later) (48). The nAchR is a widely disseminated receptor in the peripheral nervous system, located on the post-synaptic membrane of NMJs (5). The discovery of the nAchR-RABV interaction was soon solidified by immunofluorescence and electron microscope evidence which showed fixed RABV localizing to NMJs in vivo (49). A RABV-G-nAchR binding site was subsequently identified: further evidence for a RABV-G-mediated entry mechanism (50).

Curiously, the nAchR is located at postsynaptic muscle membranes and not presynaptic nerve membranes as initially suspected. This suggests that RABV has conserved a strategy of local replication in the muscle prior to neuroinvasion (31). By concentrating virus at an NMJ, or exposing additional NMJs to viral particles, CNS uptake may be more likely (51). This may also explain the long incubation periods of natural RABV infections, where a latent or low-replication stage of RABV may occur in muscle cells. Such a hypothesis is supported by experiments in which street-virus RABV replication occurred in vivo despite denervation of the inoculated muscle $(52,53)$. However, entry of RABV from the periphery into the CNS without prior local replication has also been observed in laboratory animals inoculated with fixed RABV $(54,55)$. 
The relative contribution to human rabies made by latent or low-replication RABV in muscle, or direct neuronal infection, is not currently known. This is an important ongoing question in the field, as it may influence the efficacy of RABV-targeted interventions. For example, a drug that does not penetrate the CNS may be effective if RABV replicates locally in muscle before entering a neuron, but will fail if RABV enters the CNS directly after exposure.

It is thought that RABV penetrates the nervous system exclusively through primary motor neurons, and not sensory or autonomic neurons (32). The field of RABV transneuronal tracing, where RABV spread is closely monitored, has provided much of the evidence for this hypothesis. For example, fixed RABV was used to map muscles controlling eye movement in guinea pigs (36), the facial and bulbospongiosus muscles of rats $(56,57)$, and the motor innervation of primate hand muscle (58). RABV was found to label only motor neurons in these studies. This hypothesis is complicated by conflicting results elsewhere, however. After intramuscularly inoculating mice with a fixed strain of RABV, another group found simultaneous infection of sensory and motor neurons at early timepoints post infection (54). Another study, where fixed RABV was inoculated into the mouse footpad, found RABV antigen in DRG sensory neurons (59), albeit at a timepoint (72 hours postinfection) which could indicate reciprocal spread of RABV between the motor to the sensory routes, not primary infection of sensory neurons (54).

The expression pattern of the peripheral RABV receptor, $n A c h R$, may clarify this issue. The $\mathrm{nAchR}$ is present on post-synaptic motor endplates, and does not play a role in transmitting signals from sensory neurons (32). Therefore, it follows that RABV particles may become concentrated at NMJs, rather than sensory endings, and will first penetrate the nervous system through a primary motor neuron $(5,32)$. It should be noted that these circumstances are only relevant for the first stages of RABV infections. At later stages of infection, the distinction between motor and sensory pathways becomes irrelevant as the virus spreads in the CNS centrifugally towards its end organs, and is readily detected in both motor and sensory neurons (32).

\section{5) RABV axonal transport}

Even before humankind understood what viruses were and how they caused disease, RABV was suspected to be an agent that traveled through nervous tissue (1). Early studies of axonal transport used the drug colchicine as an inhibitor of axoplasmic flow, which we now know occurs by inhibiting microtubule polymerization. The inhibition of RABV propagation through a colchicine-treated rat sciatic nerve provided early evidence for RABV retrograde axonal transport $(60,61)$.

In recent years, studies of RABV-G and -P structure and host cell interactions have guided research in RABV axonal transport mechanisms. It was found that RABV-G is sufficient to confer retrograde axonal spread to a pseudotyped lentivirus vector, and also to a VSV deleted of its own $\mathrm{G}$ and transcomplemented with RABV-G $(30,62)$. This is strong evidence of a role for RABV-G in retrograde axonal transport. A screen for lyssavirus P interacting proteins revealed an interaction between RABV-P and the cytoplasmic dynein light chain 
(LC8), a protein involved in minus-end-directed microtubule transport $(63,64)$. This evidence suggests a mechanism for RABV retrograde transport involving a dynein- RABV-P interaction (dynein is a family of motor proteins that transport cargo in a retrograde manner). However, deletion of RABV-P's LC8-binding site did not abrogate transport of RABV from the peripheral site of inoculation to the brain. This was taken as evidence of other microtubule-virus interactions that have yet to be described $(65,66)$.

RABV axonal transport has been directly observed with live cell in vitro imaging. RABV containing a fluorescently labeled $\mathrm{G}$ was observed travelling in neuronal processes completely enveloped in endosomal vesicles, confirming the repurposing of intracellular transport mechanisms by one or more viral proteins (67). Another study using compartmentalized rat DRGs showed efficient anterograde transport of RABV subsequent to retrograde transport and viral replication in the cell soma (68). This complicates the concept of RABV as a virus which is transported in only a retrograde fashion, which has been taken for granted by researchers employing rabies as a transneuronal tracer (32). However, the most likely contribution of anterograde transport is in late-stage infections, where multiorgan deposition of rabies virus is observed (34). The consequences of anterograde transport to early events in the rabies life cycle, such as neuroinvasion or spread through the CNS, remains controversial.

\section{6) Rabies virus trans-synaptic spread}

When infecting a host organism, viruses are confronted with a complex mosaic of cell types, only some of which may be susceptible to infection, as well as intrinsic and innate host defenses (46). One way to look at RABV tropism is to consider the advantage a virus derives from accessing a densely connected network of related cells such as neurons. Furthermore, as a non-renewable cell population, neurons have evolved mechanisms (such as the BBB) to protect themselves from cytotoxic immune effectors such as CD8+ T cells, which may otherwise recognize and destroy a virus-infected cell (42).

As discussed earlier, the unique features of RABV once inside the CNS are exclusive infection of neurons, trans-synaptic spread, and lack of apparent damage to infected tissue (32). Studies of these phenomena have yielded diverse insights into RABV-host cell interactions. The cellular tropism of RABV, for example, is thought to be determined by the virus' ability to bind to at least two cell surface targets specific to neurons, the neuronal cell adhesion molecule (NCAM) and p75NTR (recall that the other cellular receptor, nAchR, is only present on post-synaptic membranes and therefore is most likely to play a role in entry into muscle cells, not neurons) $(48,69,70)$. Because deletion of these viral receptors does not entirely abrogate RABV infection in vivo, it is likely that RABV uses these receptors in combination with other molecules such as carbohydrates, gangliosides, and lipids (71), or that other receptors may exist to facilitate entry. In the face of this incomplete picture, another way to approach the study of tropism is to study the viral ligand of the cellular receptor - RABV glycoprotein (RABV-G). 


\section{7) Role of RABV-G in viral tropism and pathogenicity}

Shortly after its characterization as a RABV surface protein, it was observed that anti-

RABV-G monoclonal antibodies protected laboratory animals from RABV challenge (72).

This had substantive implications for contemporary vaccine design, but also offered an indirect means of examining the puzzle of RABV pathogenicity. By chemically mutagenizing the virus and screening for RABV that escaped neutralization by these antibodies, researchers generated a panel of fixed RABV-G mutants with reduced virulence $(73,74)$. These pathogenic and apathogenic counterpart strains have continued to enable investigations into RABV-G as a molecular determinant of pathogenicity. One mutant discovered in this manner, which substitutes RABV-G's position 333 arginine with glutamate or isoleucine, has become a well-studied model of G-mediated RABV attenuation $(54,75,76)$. The G-333 mutant displays stunted spreading, infecting primary motoneurons following intramuscular inoculation but becoming blocked after the first cycle of infection (54).

These first-generation RABV-G mutants are all tissue-culture adapted virus strains, which raises the concern that they do not recapitulate natural infections (77). The recovery of infectious RABV from cDNA clones has allowed researchers to make more precise changes to the viral genome, and to manipulate wild-type isolates without extensive passage in tissue culture. For instance, one study exchanged the RABV-G of a fixed, nonpathogenic strain of RABV (SN-10) with the RABV-G of a bat-associated street virus (SHBRV), or that of two different fixed but pathogenic strains (CVS-N2c and CVS-B2c) (77). This resulted in significant, but incomplete, restoration of the pathogenic phenotype after intramuscular inoculation of mice for each of the chimeric viruses. Similar results were observed with the substitution of SN-10's G and M together for SHBRV's, or several other combinations (78, 79). Together, these results suggest that RABV pathogenicity is partially, but not exclusively, determined by $\mathrm{G}$.

\section{8) RABV immune evasion}

RABV, like all pathogens, has co-evolved with the sophisticated immune systems of its hosts. As discussed previously, the tropism of RABV for an immunologically isolated tissue is, itself, an immune evasion strategy. RABVs that replicate at lower levels in vivo and that cause less overt tissue damage are often found to be more pathogenic (80-82). Therefore, it seems that RABV is evading the adaptive immune system by "staying under the radar". Some mechanisms of this adaptive immune evasion have been studied, such as the RABVinduced apoptosis of CNS-infiltrating lymphocytes during infection or a possible manipulation of BBB permeability.

RABV also needs to escape innate immunity, which is highly conserved in all mammalian cells and might be even more important in neurons. For these reasons, RABV directly disrupts inter- and intracellular signaling pathways involved in host cell defense. The best known and understood of these is the disruption of interferon (IFN) signaling by RABV-P, a mechanism of innate immune evasion. 


\section{RABV and the interferon response}

Most mammalian cells can detect viral infections through pattern-recognition receptors (PRRs), which stimulate production of type I IFN (includes IFNa and IFN $\beta$ ) $(18,83,84)$. IFNs act in an autocrine and paracrine manner to induce expression of interferon stimulated genes (ISGs), which have diverse antiviral functions $(84,85)$. The importance of the IFN system in the context of RABV infections was demonstrated by the increased susceptibility to RABV of mice given IFN-blocking immunoglobulin, and also of type I IFN receptor knockout mice (Ifnar ${ }^{--}$) for RABV $(86,87)$. The fact that Ifnar ${ }^{-/}$mice have elevated or faster morbidity after both peripheral and central inoculations $(86,88)$ suggests that IFN acts as an anti-RABV defense mechanism at both the levels of initial neuroinvasion and intraCNS spread.

Researchers have elucidated two distinct mechanisms of IFN inhibition by RABV, both mediated by RABV-P: inhibition of initial IFN induction, and downstream induction of ISGs. This involves the binding by RABV-P of cytoplasmic signal transducers and nuclear transcription factors, requiring both cytoplasmic and nuclear forms of $\mathrm{P}$. This is accomplished by RABV by the use of internal start codons. Full-length $P$ has a nuclear import and a nuclear export sequence, but a truncated form of $\mathrm{P}$ lacking the nuclear export sequence is also produced, and therefore is trafficked to and remains in the nucleus $(18,89)$.

The first of the P-mediated IFN inhibitory mechanisms to be discovered was the nuclear binding of IRF3 (Interferon Regulatory Factor 3) $(18,90)$. IRFs are transcription factors that activate IFN production in response to upstream detection of viral nucleic acids; RABV-P prevents IRF activation, blocking the IFN response (18). The first evidence of this was the observation that RABVs engineered to express low levels of $\mathrm{P}$ induced higher levels of IFN production (91). A follow-up study showed that truncated P also induces high levels of IFN, but that IFN inhibition can be restored by complementing with full-length $\mathrm{P}$, and linked this effect in vitro to a possible IRF3-RABV-P protein-protein interaction (90). This interaction was later confirmed and mapped to specific sites on RABV-P (92).

In addition to counteracting transcription of IFN, RABV has a separate mechanism to prevent cells from responding to IFN. RABV-P sequesters the transcription factor STAT 122 (a heterodimer) in the cytoplasm, preventing it from reaching its nuclear ISG target promoters (93). The interaction between RABV-P and STATs was mapped to sites on RABV-P that were distinct from the IRF interaction (92). Additionally, the nuclear form of $\mathrm{P}$ responsible for IRF binding also binds STAT1 in the nucleus, implicating a separate, nuclear inhibition mechanism for STAT1 (94). This mechanism is conserved across several lyssavirus species (10).

Predictably, RABV-P is a determinant of RABV pathogenicity. This has been studied using chimeric viruses, similar to the exchanges of RABV-G between pathogenic and nonpathogenic strains described previously. In one study, a fixed RABV which killed laboratory animals after intracranial injection was attenuated by repeated passage in cell culture (95). When the $\mathrm{P}$ protein of the pathogenic parent strain was inserted into its nonpathogenic derivative, pathogenicity was restored. The attenuated strain was found to be specifically impaired for blocking STAT nuclear translocation, directly linking STAT inhibition to 
pathogenicity. A follow-up study recapitulated these data after intramuscular infections, showing that STAT inhibition by RABV is also important in the neuroinvasion step of RABV infections (96).

\section{Importance of CNS-infiltrating lymphocytes in controlling RABV}

The migration of lymphocytes into the CNS has been implicated in the control of several neurotropic pathogens, RABV included (80). Although the means by which T or B cells "clear" a RABV infection in the CNS are still not known, the importance of these migratory cells is becoming evident. For instance, peripheral inoculation of nude mice, which lack functional T lymphocytes, with a normally-apathogenic RABV results in a fatal outcome (97). In contrast, the presence or absence of functional lymphocytes does not change the outcome of a pathogenic RABV peripheral inoculation (98). One explanation for this result is that apathogenic RABV activates $\mathrm{T}$ cells in the periphery prior to neuroinvasion, preventing the virus from entering the CNS in a T cell dependent manner. However, differences in immune response, in terms of neutralizing antibody titers, do not necessarily differ between peripherally administered strains of different pathogenicity $(80,99)$. Rather, it is also possible that RABV gene products actively block the entry or survival of lymphocytes in the CNS.

Entry of immune effectors may be blocked at the level of the BBB. A difference in pathogenicity between two RABV strains may be explained by the difference in BBB permeability to lymphocyte chemoattractants (100). By maintaining a higher level of BBB integrity, wild-type RABV may block lymphocyte diapedesis across the neurovascular epithelium, and prevent them from accessing RABV-infected neurons $(100,101)$. In a comparison of several RABV strains, researchers found significant lymphocyte CNS infiltration and increased BBB permeability in animals infected with attenuated RABV, but not following infection with any pathogenic RABVs (101). Additionally, increasing BBB permeability during wild-type RABV infection increased survival (102). However, it is still not known if this means that pathogenic RABVs have an active mechanism for maintaining BBB integrity. It is also possible that the attenuated RABV has gained an immunostimulatory property that triggers a "danger signal", resulting in immune cell infiltration and viral clearance.

There is also evidence that RABV infected cells are stimulated to kill CNS-infiltrating lymphocytes. When comparing peripherally administered pathogenic and attenuated fixed RABV strains (CVS and Pasteur Virus, respectively), one group observed that although both viruses triggered $\mathrm{CD} 4+$ and $\mathrm{CD} 8+\mathrm{T}$ cell $\mathrm{CNS}$ infiltration, migratory $\mathrm{T}$ cells were lost over the course of pathogenic RABV infection, while they continued to accumulate in the transient infection (103). This loss corresponded to an increase in $\mathrm{T}$ cell apoptosis, indicating that lymphocytes were able to invade the BBB, but not survive in the CNS. Deletion of the cell-surface molecule FasL, a major trigger of $\mathrm{T}$ cell apoptosis in the normal immune system, abrogated this effect and increased survival after pathogenic fixed virus challenge (103). A similar reduction of RABV virulence was observed in mice lacking B7$\mathrm{H} 1$, another natural inhibitor of $\mathrm{T}$ cell responses (104). 


\section{9) Neuropathogenicity and spread of RABV}

Despite much research into RABV biology, the mechanism by which RABV infection causes fatal disease is still not known. As noted earlier, symptomatic rabies patients die with only mild histological lesions in the brain, and without significant loss of neurons (105). The immune evasion strategies outlined above explain a part of this situation: RABV seems to avoid inflammatory or cytolytic host defense, and may lose its ability to cause disease if apoptosis, local inflammation, or lymphocyte diapedesis is restored $(80-82,106)$. Therefore, RABV's 'invisibility' can be regarded as a successful adaptation. It is likely that wild-type RABV-induced neuronal dysfunction may not depend on any known immune response (i.e. viral proteins alone may be responsible for it).

Researchers approach the study of this neuronal dysfunction in a number of ways, mainly morphological, metabolic, and molecular genetic analysis. These lines of research most directly address the central mystery of RABV pathogenesis, with are the gross behavioral changes and death that occur in human clinical rabies cases.

\section{Morphological, metabolic, and genetic analysis of infected cells}

For many years, the major observation that distinguished RABV infected and normal cells was the appearance of cytoplasmic inclusions called Negri bodies, named for the researcher who described them in 1903. Negri bodies are now known to be centers of RABV translation and replication, and contain at least one cellular protein, Hsp70, with a positive role in viral production $(107,108)$. However, despite their clear role in the RABV life cycle, the known properties of Negri bodies do not explain the aberrant phenotype of RABVinfected neurons.

More details have emerged with advances in labeling and microscopy. In one study, degeneration of axons or dendrites - indicated by obvious disorganization or disappearance during microscopy, and loss of microtubule and neurofilament specific immunostaining was observed in animals peripherally inoculated with a pathogenic fixed virus, but not following infection with an attenuated fixed virus (109). Consistent with other studies, this degeneration occurred without evidence of inflammation or apoptosis. When another team used fluorescently labeled recombinant RABV in a similar system, infected neurons displayed bead-like swellings in neuronal processes, especially axons (110).

These morphological changes in infected cells have been linked to metabolic changes. One report recapitulated the axonal swelling phenotype in mouse dorsal root ganglion (DRG) cells cultured ex vivo, infected by pathogenic fixed RABV (111). In addition to RABV antigen, these swellings were found to contain aggregations of mitochondria and markers of oxidative stress, characteristics of sensory neurons in the context of diabetic neuropathy $(111,112)$. A follow-up study gathered evidence that RABV- infected cells, including DRGs, have increased generation of potentially toxic reactive oxygen species (ROS) during normal cellular metabolism (113). The loss of neuronal structural integrity suggested by these studies is especially interesting. Because one of the defining features of the CNS is its connectedness, a pathogen that physically disrupts axons or dendrites could cause major damage to the CNS without killing any cells by affecting neuronal networks, for example. 
The tools of modern genetic analysis have recently been brought to bear on this question as well. Our laboratory's recent study used a virally expressed Cre recombinase-based reporter system to permanently mark RABV-infected neurons in vivo (114). To the existing techniques of viral antigen staining and fluorescently labeled virus, this reporter system adds a noninvasive and permanent way of marking infected cells. Transgenic mice are used that express a fluorescent TdTomato protein in all cells. This gene is flanked by loxP sites such that in the presence of a functional cre recombinase, the intervening sequence is removed, the expression of TdTomato is lost, and the expression of a downstream GFP gene is induced. This reflects a somatic cellular change indicative of infection, and would remain even if the virus is eventually cleared. This is a promising method for studying RABV spread to various brain regions. In this approach, neurons which were once infected with RABV and which had cleared the virus can be separated from uninfected neurons using FACS, and the transcriptome changes between these two cell populations were analyzed by microarray. This yielded a large data set which researchers can use to probe the molecular genetics of RABV neuronal dysfunction.

\section{Late stages of infection: behavioral changes, centrifugal spread of RABV, and death}

Human cases of rabies present across a spectrum of clinical forms, roughly divided into "furious" or "paralytic" (1). Briefly, furious rabies refers to classical rabies symptoms, including severe agitation and hydrophobia (1). During the course of several days, this phase of excitement subsides into worsening paralysis and impaired consciousness, and finally coma. Death occurs by cardiac arrest, circulatory insufficiency, or respiratory failure. In paralytic rabies, ascending paralysis is the principal presenting feature, followed by similar progression into coma. Both phenotypes may be observed in laboratory animals following infection, sometimes unpredictably with the same strain of virus and method of administration (B. Davis, unpublished observation). The same may be true of natural RABV infections: in one report, furious and paralytic rabies were observed in two human patients after exposure to the same rabid $\operatorname{dog}(115)$.

In the past, the behavioral changes observed following RABV infection have been ascribed to the observation that RABV preferentially infects the structures associated with the limbic system, responsible for aspects of emotion and motivation (46). However, there is no evidence that RABV is more able to infect the neurons of one brain region or another (Peter Strick, personal communication). Rather, it is more likely that this observation is due to the closer synaptic connectivity of these regions with the common sites of RABV entry. In either case, rabies-associated aggression seems to make transmission of RABV more likely, especially given the synchronous shedding of the virus into saliva.

In the late stages of infection, the spread of RABV to salivary glands occurs alongside the "centrifugal" propagation of RABV to diverse end organs, such as skin, hair follicles, and muscle fibers observed $(32,35)$. In order to reach the salivary gland from the CNS, RABV needs to travel in an anterograde fashion through autonomic sensory glanglia - an inversion of the unidirectional (retrograde) propagation of RABV observed early in infection (32). RABV enters the saliva by budding from the apical plasma membranes of mucous cells, an 
apparent loss of strict neurotropism (116). These changes highlight the sharp differences between RABV phenotype early and late in infection.

Rabies presents with some variation across species (117). Small mammals such as bats may have milder, more prolonged disease progression or even recover from rabies $(118,119)$. Nonfatal or abortive human rabies cases are more controversial. In case reports of patients surviving clinical rabies, partial resistance from previous exposure plays an ambiguous role alongside intensive care (120). Naturally acquired resistance to RABV was suggested by a study of two communities in rural Peru, where unvaccinated but seropositive individuals were observed (121). For the most part, however, knowledge of nonfatal RABV exposures or disease has not changed the grim prognosis for clinical rabies patients. Outcomes in human rabies patients seem to be similar among individuals infected by large or by small mammals, despite any reported differences in the infectiousness of RABV strains associated with these animals $(1,122)$. This suggests that 1$)$ the RABV causes similar damage at the cellular level in all mammals, but presents differently due to differences in CNS architecture, and/or 2) that RABV can initiate distinct diseases depending on the host organism. Neuronal dysfunction may be a consequence of disruption or deregulation of particular neuronal networks or pathways. A better understanding of both RABV cellular pathogenesis and synaptic connectivity is required before these concepts can be meaningfully related to each other.

\section{0) Outlook and future directions}

Unraveling the mystery of RABV neuropathogenesis is still ongoing despite many years of research. However, the advancements made during the past few years hold great promise for the field. The structure and life cycle of RABV are now well understood, an important step in enabling efforts to develop interventions that block replication or budding of the virus. Moreover, the ability to experimentally manipulate the RABV genome by reverse genetics allows researchers to link pathogenicity to specific sites in the viral genome. These genetic determinants of pathogenicity are themselves becoming better understood, given progress in fields such as RABV neuroinvasive mechanisms, intracellular targeting, and immune evasion. Furthermore, advances in in vitro imaging have recently allowed researchers to observe RABV travelling through host cells at high resolution. The same may be said about RABV spread through different brain regions, which is becoming easier to visualize. Finally, the powerful toolbox of modern high-throughput genetics platforms, such as microarray, has just begun to be applied to the field of RABV host-cell interactions.

It is hoped that the next generation of RABV virologists will integrate these advancements with the central observations about the unique disease. For this to occur, researchers will have to somehow connect these observations with the ways RABV uses neurons not just as a substrate - as most other neurotropic viruses seem to - but as a platform for manipulation of target cells.

\section{Acknowledgments}

Work in the investigator laboratory is supported in part by NIH grants R01AI105204, R21NS074006, R42AI073064, P40RR018604 and the Jefferson Vaccine Center to MJS. 


\section{References}

1. Nicholson KG. 1994 Human Rabies In Handbook of Neurovirology, ed. McKendall RR, Stroop WG, pp. 463-80. New York, NY: Marcel Dekker, Inc.

2. Kuzmin IV, Tordo N. 2012 Genus Lyssavirus In Rhabdoviruses: Molecular Taxonomy, Evolution, Genomics, Ecology, Host-Vector Interactions, Cytopathology and Control, pp. 37-58. Norfolk, UK: Caister Academic Press

3. Rosner F 1974 Rabies in the Talmud. Med Hist 18: 198-200 [PubMed: 4606976]

4. Knobel DL, Cleaveland S, Coleman PG, Fevre EM, Meltzer MI, Miranda ME, Shaw A, Zinsstag J, Meslin FX. 2005 Re-evaluating the burden of rabies in Africa and Asia. Bull World Health Organ 83: 360-8 [PubMed: 15976877]

5. Schnell MJ, McGettigan JP, Wirblich C, Papaneri A. 2010 The cell biology of rabies virus: using stealth to reach the brain. Nat Rev Microbiol 8: 51-61 [PubMed: 19946287]

6. Wildy P 1971 Classification and nomenclature of viruses. First report of the International Committee on Nomenclature of Viruses. Monographs in Virology 5: 51

7. Dietzgen RG. 2012 Morphology, Genome Organization, Transcription and Replication of Rhabdoviruses In Rhabdoviruses: Molecular Taxonomy, Evolution, Genomics, Ecology, HostVector Interactions, Cytopathology and Control, ed. Dietzgen RG, Kuzmin IV, pp. 5-12. Norfolk, UK: Caister Academic Press

8. Marston DA, McElhinney LM, Banyard AC, Horton DL, Nunez A, Koser ML, Schnell MJ, Fooks AR. 2013 Interspecies protein substitution to investigate the role of the lyssavirus glycoprotein. J Gen Virol 94: 284-92 [PubMed: 23100360]

9. Pollin R, Granzow H, Kollner B, Conzelmann KK, Finke S. 2013 Membrane and inclusion body targeting of lyssavirus matrix proteins. Cell Microbiol 15: 200-12 [PubMed: 23046288]

10. Wiltzer L, Larrous F, Oksayan S, Ito N, Marsh GA, Wang LF, Blondel D, Bourhy H, Jans DA, Moseley GW. 2012 Conservation of a unique mechanism of immune evasion across the Lyssavirus genus. J Virol 86: 10194-9 [PubMed: 22740405]

11. Nolden T, Banyard AC, Finke S, Fooks AR, Hanke D, Hoper D, Horton DL, Mettenleiter TC, Muller T, Teifke JP, Freuling CM. 2014 Comparative studies on the genetic, antigenic and pathogenic characteristics of Bokeloh bat lyssavirus. J Gen Virol 95: 1647-53 [PubMed: 24828330]

12. Rahmeh AA, Schenk AD, Danek EI, Kranzusch PJ, Liang B, Walz T, Whelan SP. 2010 Molecular architecture of the vesicular stomatitis virus RNA polymerase. Proc Natl Acad Sci U S A 107: 20075-80 [PubMed: 21041632]

13. Hummeler K, Tomassini N, Sokol F, Kuwert E, Koprowski H. 1968 Morphology of the nucleoprotein component of rabies virus. J Virol 2: 1191-9 [PubMed: 4881422]

14. Lenard J, Vanderoef R. 1990 Localization of the membrane-associated region of vesicular stomatitis virus $\mathrm{M}$ protein at the $\mathrm{N}$ terminus, using the hydrophobic, photoreactive probe $125 \mathrm{I}-$ TID. J Virol 64: 3486-91 [PubMed: 2161951]

15. Mebatsion T, Weiland F, Conzelmann KK. 1999 Matrix protein of rabies virus is responsible for the assembly and budding of bullet-shaped particles and interacts with the transmembrane spike glycoprotein G. J Virol 73: 242-50 [PubMed: 9847327]

16. Zakowski JJ, Wagner RR. 1980 Localization of membrane-associated proteins in vesicular stomatitis virus by use of hydrophobic membrane probes and cross-linking reagents. J Virol 36: 93-102 [PubMed: 6255216]

17. Dietzgen RG, Kuzmin IV. 2012 Taxonomy of Rhabdoviruses In Rhabdoviruses: Molecular Taxonomy, Evolution, Genomics, Ecology, Host-Vector Interactions, Cytopathology and Control, ed. Dietzgen RG, Kuzmin IV, pp. 13-22. Norfolk, UK: Caister Academic Press

18. Rieder M, Conzelmann KK. 2011 Interferon in rabies virus infection. Adv Virus Res 79: 91-114 [PubMed: 21601044]

19. Etessami R, Conzelmann KK, Fadai-Ghotbi B, Natelson B, Tsiang H, Ceccaldi PE. 2000 Spread and pathogenic characteristics of a G-deficient rabies virus recombinant: an in vitro and in vivo study. J Gen Virol 81: 2147-53 [PubMed: 10950970] 
20. Le Blanc I, Luyet PP, Pons V, Ferguson C, Emans N, Petiot A, Mayran N, Demaurex N, Faure J, Sadoul R, Parton RG, Gruenberg J. 2005 Endosome-to-cytosol transport of viral nucleocapsids. Nat Cell Biol 7: 653-64 [PubMed: 15951806]

21. Ivanov I, Yabukarski F, Ruigrok RW, Jamin M. 2011 Structural insights into the rhabdovirus transcription/replication complex. Virus Res 162: 126-37 [PubMed: 21963663]

22. Banerjee AK, Barik S. 1992 Gene expression of vesicular stomatitis virus genome RNA. Virology 188: 417-28 [PubMed: 1316668]

23. Finke S, Cox JH, Conzelmann KK. 2000 Differential transcription attenuation of rabies virus genes by intergenic regions: generation of recombinant viruses overexpressing the polymerase gene. J Virol 74: 7261-9 [PubMed: 10906180]

24. Liu P, Yang J, Wu X, Fu ZF. 2004 Interactions amongst rabies virus nucleoprotein, phosphoprotein and genomic RNA in virus-infected and transfected cells. J Gen Virol 85: 3725-34 [PubMed: 15557246]

25. Finke S, Mueller-Waldeck R, Conzelmann KK. 2003 Rabies virus matrix protein regulates the balance of virus transcription and replication. J Gen Virol 84: 1613-21 [PubMed: 12771432]

26. Abraham G, Banerjee AK. 1976 Sequential transcription of the genes of vesicular stomatitis virus. Proc Natl Acad Sci U S A 73: 1504-8 [PubMed: 179088]

27. Mebatsion T, Konig M, Conzelmann KK. 1996 Budding of rabies virus particles in the absence of the spike glycoprotein. Cell 84: 941-51 [PubMed: 8601317]

28. Okumura A, Harty RN. 2011 Rabies virus assembly and budding. Adv Virus Res 79: 23-32 [PubMed: 21601040]

29. Hastie E, Cataldi M, Marriott I, Grdzelishvili VZ. 2013 Understanding and altering cell tropism of vesicular stomatitis virus. Virus Res 176: 16-32 [PubMed: 23796410]

30. Beier KT, Saunders AB, Oldenburg IA, Sabatini BL, Cepko CL. 2013 Vesicular stomatitis virus with the rabies virus glycoprotein directs retrograde transsynaptic transport among neurons in vivo. Front Neural Circuits 7: 11 [PubMed: 23403489]

31. Lafon M 2005 Rabies virus receptors. J Neurovirol 11: 82-7 [PubMed: 15804965]

32. Ugolini G 2011 Rabies virus as a transneuronal tracer of neuronal connections. Adv Virus Res 79: 165-202 [PubMed: 21601048]

33. Jackson AC, Ye H, Phelan CC, Ridaura-Sanz C, Zheng Q, Li Z, Wan X, Lopez-Corella E. 1999 Extraneural organ involvement in human rabies. Lab Invest 79: 945-51 [PubMed: 10462032]

34. Jogai S, Radotra BD, Banerjee AK. 2002 Rabies viral antigen in extracranial organs: a postmortem study. Neuropathol Appl Neurobiol 28: 334-8 [PubMed: 12175346]

35. Macedo CI, Carnieli P Jr, Brandao PE, Travassos da Rosa ES, Oliveira Rde N, Castilho JG, Medeiros R, Machado RR, Oliveira RC, Carrieri ML, Kotait I. 2006 Diagnosis of human rabies cases by polymerase chain reaction of neck-skin samples. Braz J Infect Dis 10: 341-5 [PubMed: 17293923]

36. Graf W, Gerrits N, Yatim-Dhiba N, Ugolini G. 2002 Mapping the oculomotor system: the power of transneuronal labelling with rabies virus. Eur J Neurosci 15: 1557-62 [PubMed: 12028367]

37. Wilbur LAAntf MFA 1996 The NIH test for potency In Laboratory techniques in rabies, ed. Meslin F-XK, M. M.; Koprowski H, pp. 360-8. Geneva, Switzerland: World Health Organization

38. Schnell MJ, Tan GS, Dietzschold B. 2005 The application of reverse genetics technology in the study of rabies virus (RV) pathogenesis and for the development of novel RV vaccines. $\mathbf{J}$ Neurovirol 11: 76-81

39. Davis AD, Jarvis JA, Pouliott CE, Morgan SM, Rudd RJ. 2013 Susceptibility and pathogenesis of little brown bats (Myotis lucifugus) to heterologous and homologous rabies viruses. J Virol 87: 9008-15 [PubMed: 23741002]

40. Morimoto K, Patel M, Corisdeo S, Hooper DC, Fu ZF, Rupprecht CE, Koprowski H, Dietzschold B. 1996 Characterization of a unique variant of bat rabies virus responsible for newly emerging human cases in North America. Proc Natl Acad Sci U S A 93: 5653-8 [PubMed: 8643632]

41. Schnell MJ, Mebatsion T, Conzelmann KK. 1994 Infectious rabies viruses from cloned cDNA. EMBO J 13: 4195-203 [PubMed: 7925265] 
42. O'Donnell LA, Rall GF. 2010 Blue moon neurovirology: the merits of studying rare CNS diseases of viral origin. J Neuroimmune Pharmacol 5: 443-55 [PubMed: 20419352]

43. Bearer EL, Breakefield XO, Schuback D, Reese TS, LaVail JH. 2000 Retrograde axonal transport of herpes simplex virus: evidence for a single mechanism and a role for tegument. Proc Natl Acad Sci U S A 97: 8146-50 [PubMed: 10884436]

44. Kramer T, Enquist LW. 2013 Directional spread of alphaherpesviruses in the nervous system. Viruses 5: 678-707 [PubMed: 23435239]

45. Fredericksen BL. 2014 The neuroimmune response to West Nile virus. J Neurovirol 20: 113-21 [PubMed: 23843081]

46. Johnson RT. 1998 Viral infections of the nervous system. Philadelphia: Lippincott-Raven. xiv, 527 p. pp.

47. Preuss MA, Faber ML, Tan GS, Bette M, Dietzschold B, Weihe E, Schnell MJ. 2009 Intravenous inoculation of a bat-associated rabies virus causes lethal encephalopathy in mice through invasion of the brain via neurosecretory hypothalamic fibers. PLoS Pathog 5: e1000485 [PubMed: 19543379]

48. Lentz TL, Burrage TG, Smith AL, Crick J, Tignor GH. 1982 Is the acetylcholine receptor a rabies virus receptor? Science 215: 182-4 [PubMed: 7053569]

49. Burrage TG, Tignor GH, Smith AL. 1985 Rabies virus binding at neuromuscular junctions. Virus Res 2: 273-89 [PubMed: 3890406]

50. Bracci L, Antoni G, Cusi MG, Lozzi L, Niccolai N, Petreni S, Rustici M, Santucci A, Soldani P, Valensin PE, et al. 1988 Antipeptide monoclonal antibodies inhibit the binding of rabies virus glycoprotein and alpha-bungarotoxin to the nicotinic acetylcholine receptor. Mol Immunol 25: 881-8 [PubMed: 3062388]

51. Watson HD, Tignor GH, Smith AL. 1981 Entry of rabies virus into the peripheral nerves of mice. J Gen Virol 56: 372-82 [PubMed: 7031182]

52. Charlton KM, Casey GA. 1981 Experimental rabies in skunks: persistence of virus in denervated muscle at the inoculation site. Can J Comp Med 45: 357-62 [PubMed: 7337867]

53. Charlton KM, Nadin-Davis S, Casey GA, Wandeler AI. 1997 The long incubation period in rabies: delayed progression of infection in muscle at the site of exposure. Acta Neuropathol 94: 73-7 [PubMed: 9224533]

54. Coulon P, Derbin C, Kucera P, Lafay F, Prehaud C, Flamand A. 1989 Invasion of the peripheral nervous systems of adult mice by the CVS strain of rabies virus and its avirulent derivative AvO1. J Virol 63: 3550-4 [PubMed: 2664219]

55. Shankar V, Dietzschold B, Koprowski H. 1991 Direct entry of rabies virus into the central nervous system without prior local replication. J Virol 65: 2736-8 [PubMed: 2016778]

56. Morcuende S, Delgado-Garcia JM, Ugolini G. 2002 Neuronal premotor networks involved in eyelid responses: retrograde transneuronal tracing with rabies virus from the orbicularis oculi muscle in the rat. J Neurosci 22: 8808-18 [PubMed: 12388587]

57. Tang Y, Rampin O, Giuliano F, Ugolini G. 1999 Spinal and brain circuits to motoneurons of the bulbospongiosus muscle: retrograde transneuronal tracing with rabies virus. J Comp Neurol 414: 167-92 [PubMed: 10516590]

58. Rathelot JA, Strick PL. 2006 Muscle representation in the macaque motor cortex: an anatomical perspective. Proc Natl Acad Sci U S A 103: 8257-62 [PubMed: 16702556]

59. Velandia-Romero ML, Castellanos JE, Martinez-Gutierrez M. 2013 In vivo differential susceptibility of sensory neurons to rabies virus infection. J Neurovirol

60. Tsiang H 1979 Evidence for an intraaxonal transport of fixed and street rabies virus. J Neuropathol Exp Neurol 38: 286-99 [PubMed: 86604]

61. Bulenga G, Heaney T. 1978 Post-exposure local treatment of mice infected with rabies with two axonal flow inhibitors, colchicine and vinblastine. J Gen Virol 39: 381-5 [PubMed: 77308]

62. Mazarakis ND, Azzouz M, Rohll JB, Ellard FM, Wilkes FJ, Olsen AL, Carter EE, Barber RD, Baban DF, Kingsman SM, Kingsman AJ, O’Malley K, Mitrophanous KA. 2001 Rabies virus glycoprotein pseudotyping of lentiviral vectors enables retrograde axonal transport and access to the nervous system after peripheral delivery. Hum Mol Genet 10: 2109-21 [PubMed: 11590128] 
63. Jacob Y, Badrane H, Ceccaldi PE, Tordo N. 2000 Cytoplasmic dynein LC8 interacts with lyssavirus phosphoprotein. J Virol 74: 10217-22 [PubMed: 11024152]

64. Raux H, Flamand A, Blondel D. 2000 Interaction of the rabies virus P protein with the LC8 dynein light chain. J Virol 74: 10212-6 [PubMed: 11024151]

65. Rasalingam P, Rossiter JP, Mebatsion T, Jackson AC. 2005 Comparative pathogenesis of the SADL16 strain of rabies virus and a mutant modifying the dynein light chain binding site of the rabies virus phosphoprotein in young mice. Virus Res 111: 55-60 [PubMed: 15896402]

66. Tan GS, Preuss MA, Williams JC, Schnell MJ. 2007 The dynein light chain 8 binding motif of rabies virus phosphoprotein promotes efficient viral transcription. Proc Natl Acad Sci U S A 104: 7229-34 [PubMed: 17438267]

67. Klingen Y, Conzelmann KK, Finke S. 2008 Double-labeled rabies virus: live tracking of enveloped virus transport. J Virol 82: 237-45 [PubMed: 17928343]

68. Bauer A, Nolden T, Schroter J, Romer-Oberdorfer A, Gluska S, Perlson E, Finke S. 2014 Anterograde glycoprotein-dependent transport of newly generated rabies virus in dorsal root ganglion neurons. J Virol 88: 14172-83 [PubMed: 25275124]

69. Thoulouze MI, Lafage M, Schachner M, Hartmann U, Cremer H, Lafon M. 1998 The neural cell adhesion molecule is a receptor for rabies virus. J Virol 72: 7181-90 [PubMed: 9696812]

70. Tuffereau C, Benejean J, Blondel D, Kieffer B, Flamand A. 1998 Low-affinity nerve-growth factor receptor (P75NTR) can serve as a receptor for rabies virus. EMBO J 17: 7250-9 [PubMed: 9857182]

71. Tuffereau C, Schmidt K, Langevin C, Lafay F, Dechant G, Koltzenburg M. 2007 The rabies virus glycoprotein receptor p75NTR is not essential for rabies virus infection. J Virol 81: 13622-30 [PubMed: 17928338]

72. Cox JH, Dietzschold B, Schneider LG. 1977 Rabies virus glycoprotein. II. Biological and serological characterization. Infect Immun 16: 754-9 [PubMed: 408269]

73. Coulon P, Rollin P, Aubert M, Flamand A. 1982 Molecular basis of rabies virus virulence. I. Selection of avirulent mutants of the CVS strain with anti-G monoclonal antibodies. J Gen Virol 61 (Pt 1): 97-100 [PubMed: 6181189]

74. Coulon P, Rollin PE, Flamand A. 1983 Molecular basis of rabies virus virulence. II. Identification of a site on the CVS glycoprotein associated with virulence. J Gen Virol 64 Pt 3: 693-6 [PubMed: 6827249]

75. Dietzschold B, Wiktor TJ, Trojanowski JQ, Macfarlan RI, Wunner WH, Torres-Anjel MJ, Koprowski H. 1985 Differences in cell-to-cell spread of pathogenic and apathogenic rabies virus in vivo and in vitro. J Virol 56: 12-8 [PubMed: 3897571]

76. Seif I, Coulon P, Rollin PE, Flamand A. 1985 Rabies virulence: effect on pathogenicity and sequence characterization of rabies virus mutations affecting antigenic site III of the glycoprotein. J Virol 53: 926-34 [PubMed: 2579247]

77. Morimoto K, Foley HD, McGettigan JP, Schnell MJ, Dietzschold B. 2000 Reinvestigation of the role of the rabies virus glycoprotein in viral pathogenesis using a reverse genetics approach. $\mathrm{J}$ Neurovirol 6: 373-81 [PubMed: 11031690]

78. Faber M, Pulmanausahakul R, Nagao K, Prosniak M, Rice AB, Koprowski H, Schnell MJ, Dietzschold B. 2004 Identification of viral genomic elements responsible for rabies virus neuroinvasiveness. Proc Natl Acad Sci U S A 101: 16328-32 [PubMed: 15520387]

79. Pulmanausahakul R, Li J, Schnell MJ, Dietzschold B. 2008 The glycoprotein and the matrix protein of rabies virus affect pathogenicity by regulating viral replication and facilitating cell-tocell spread. J Virol 82: 2330-8 [PubMed: 18094173]

80. Lafon M 2011 Evasive strategies in rabies virus infection. Adv Virus Res 79: 33-53 [PubMed: 21601041]

81. Thoulouze MI, Lafage M, Yuste VJ, Kroemer G, Susin SA, Israel N, Lafon M. 2003 Apoptosis inversely correlates with rabies virus neurotropism. Ann N Y Acad Sci 1010: 598-603 [PubMed: 15033799]

82. Morimoto K, Hooper DC, Spitsin S, Koprowski H, Dietzschold B. 1999 Pathogenicity of different rabies virus variants inversely correlates with apoptosis and rabies virus glycoprotein expression in infected primary neuron cultures. J Virol 73: 510-8 [PubMed: 9847357] 
83. Hornung V, Ellegast J, Kim S, Brzozka K, Jung A, Kato H, Poeck H, Akira S, Conzelmann KK, Schlee M, Endres S, Hartmann G. 2006 5'-Triphosphate RNA is the ligand for RIG-I. Science 314: 994-7 [PubMed: 17038590]

84. Diamond MS, Farzan M. 2013 The broad-spectrum antiviral functions of IFIT and IFITM proteins. Nat Rev Immunol 13: 46-57 [PubMed: 23237964]

85. Der SD, Zhou A, Williams BR, Silverman RH. 1998 Identification of genes differentially regulated by interferon alpha, beta, or gamma using oligonucleotide arrays. Proc Natl Acad Sci U S A 95: 15623-8 [PubMed: 9861020]

86. Chopy D, Detje CN, Lafage M, Kalinke U, Lafon M. 2011 The type I interferon response bridles rabies virus infection and reduces pathogenicity. J Neurovirol 17: 353-67 [PubMed: 21805057]

87. Marcovistz R, Galabru J, Tsiang H, Hovanessian AG. 1986 Neutralization of interferon produced early during rabies virus infection in mice. J Gen Virol 67 (Pt 2): 387-90 [PubMed: 2418153]

88. Marschalek A, Finke S, Schwemmle M, Mayer D, Heimrich B, Stitz L, Conzelmann KK. 2009 Attenuation of rabies virus replication and virulence by picornavirus internal ribosome entry site elements. J Virol 83: 1911-9 [PubMed: 19073737]

89. Chenik M, Chebli K, Blondel D. 1995 Translation initiation at alternate in-frame AUG codons in the rabies virus phosphoprotein mRNA is mediated by a ribosomal leaky scanning mechanism. $\mathrm{J}$ Virol 69: 707-12 [PubMed: 7815533]

90. Brzozka K, Finke S, Conzelmann KK. 2005 Identification of the rabies virus alpha/beta interferon antagonist: phosphoprotein P interferes with phosphorylation of interferon regulatory factor 3 . J Virol 79: 7673-81 [PubMed: 15919920]

91. Finke S, Brzozka K, Conzelmann KK. 2004 Tracking fluorescence-labeled rabies virus: enhanced green fluorescent protein-tagged phosphoprotein $\mathrm{P}$ supports virus gene expression and formation of infectious particles. J Virol 78: 12333-43 [PubMed: 15507620]

92. Rieder M, Brzozka K, Pfaller CK, Cox JH, Stitz L, Conzelmann KK. 2011 Genetic dissection of interferon-antagonistic functions of rabies virus phosphoprotein: inhibition of interferon regulatory factor 3 activation is important for pathogenicity. J Virol 85: 842-52 [PubMed: 21084487]

93. Vidy A, Chelbi-Alix M, Blondel D. 2005 Rabies virus P protein interacts with STAT1 and inhibits interferon signal transduction pathways. J Virol 79: 14411-20 [PubMed: 16254375]

94. Vidy A, El Bougrini J, Chelbi-Alix MK, Blondel D. 2007 The nucleocytoplasmic rabies virus P protein counteracts interferon signaling by inhibiting both nuclear accumulation and DNA binding of STAT1. J Virol 81: 4255-63 [PubMed: 17287281]

95. Ito N, Moseley GW, Blondel D, Shimizu K, Rowe CL, Ito Y, Masatani T, Nakagawa K, Jans DA, Sugiyama M. 2010 Role of interferon antagonist activity of rabies virus phosphoprotein in viral pathogenicity. J Virol 84: 6699-710 [PubMed: 20427527]

96. Yamaoka S, Ito N, Ohka S, Kaneda S, Nakamura H, Agari T, Masatani T, Nakagawa K, Okada K, Okadera K, Mitake H, Fujii T, Sugiyama M. 2013 Involvement of the rabies virus phosphoprotein gene in neuroinvasiveness. J Virol 87: 12327-38 [PubMed: 24027304]

97. Galelli A, Baloul L, Lafon M. 2000 Abortive rabies virus central nervous infection is controlled by T lymphocyte local recruitment and induction of apoptosis. J Neurovirol 6: 359-72

98. Camelo S, Lafage M, Galelli A, Lafon M. 2001 Selective role for the p55 Kd TNF-alpha receptor in immune unresponsiveness induced by an acute viral encephalitis. J Neuroimmunol 113: 95-108 [PubMed: 11137581]

99. Roy A, Phares TW, Koprowski H, Hooper DC. 2007 Failure to open the blood-brain barrier and deliver immune effectors to central nervous system tissues leads to the lethal outcome of silverhaired bat rabies virus infection. J Virol 81: 1110-8 [PubMed: 17108029]

100. Hooper DC, Roy A, Barkhouse DA, Li J, Kean RB. 2011 Rabies virus clearance from the central nervous system. Adv Virus Res 79: 55-71 [PubMed: 21601042]

101. Roy A, Hooper DC. 2008 Immune evasion by rabies viruses through the maintenance of bloodbrain barrier integrity. J Neurovirol 14: 401-11 [PubMed: 19016377]

102. Roy A, Hooper DC. 2007 Lethal silver-haired bat rabies virus infection can be prevented by opening the blood-brain barrier. J Virol 81: 7993-8 [PubMed: 17507463] 
103. Baloul L, Camelo S, Lafon M. 2004 Up-regulation of Fas ligand (FasL) in the central nervous system: a mechanism of immune evasion by rabies virus. J Neurovirol 10: 372-82 [PubMed: 15765808]

104. Lafon M, Megret F, Meuth SG, Simon O, Velandia Romero ML, Lafage M, Chen L, Alexopoulou L, Flavell RA, Prehaud C, Wiendl H. 2008 Detrimental contribution of the immuno-inhibitor B7H1 to rabies virus encephalitis. J Immunol 180: 7506-15 [PubMed: 18490751]

105. Jackson AC, Randle E, Lawrance G, Rossiter JP. 2008 Neuronal apoptosis does not play an important role in human rabies encephalitis. J Neurovirol 14: 368-75 [PubMed: 19023689]

106. Faber M, Pulmanausahakul R, Hodawadekar SS, Spitsin S, McGettigan JP, Schnell MJ, Dietzschold B. 2002 Overexpression of the rabies virus glycoprotein results in enhancement of apoptosis and antiviral immune response. J Virol 76: 3374-81 [PubMed: 11884563]

107. Lahaye X, Vidy A, Pomier C, Obiang L, Harper F, Gaudin Y, Blondel D. 2009 Functional characterization of Negri bodies (NBs) in rabies virus-infected cells: Evidence that NBs are sites of viral transcription and replication. J Virol 83: 7948-58 [PubMed: 19494013]

108. Lahaye X, Vidy A, Fouquet B, Blondel D. 2012 Hsp70 protein positively regulates rabies virus infection. J Virol 86: 4743-51 [PubMed: 22345440]

109. Li XQ, Sarmento L, Fu ZF. 2005 Degeneration of neuronal processes after infection with pathogenic, but not attenuated, rabies viruses. J Virol 79: 10063-8 [PubMed: 16014967]

110. Scott CA, Rossiter JP, Andrew RD, Jackson AC. 2008 Structural abnormalities in neurons are sufficient to explain the clinical disease and fatal outcome of experimental rabies in yellow fluorescent protein-expressing transgenic mice. J Virol 82: 513-21 [PubMed: 17942540]

111. Jackson AC, Kammouni W, Zherebitskaya E, Fernyhough P. 2010 Role of oxidative stress in rabies virus infection of adult mouse dorsal root ganglion neurons. J Virol 84: 4697-705 [PubMed: 20181692]

112. Zherebitskaya E, Akude E, Smith DR, Fernyhough P. 2009 Development of selective axonopathy in adult sensory neurons isolated from diabetic rats: role of glucose-induced oxidative stress. Diabetes 58: 1356-64 [PubMed: 19252136]

113. Alandijany T, Kammouni W, Roy Chowdhury SK, Fernyhough P, Jackson AC. 2013 Mitochondrial dysfunction in rabies virus infection of neurons. J Neurovirol 19: 537-49 [PubMed: 24277436]

114. Gomme EA, Wirblich C, Addya S, Rall GF, Schnell MJ. 2012 Immune clearance of attenuated rabies virus results in neuronal survival with altered gene expression. PLoS Pathog 8: e1002971 [PubMed: 23071441]

115. Hemachudha T, Wacharapluesadee S, Laothamatas J, Wilde H. 2006 Rabies. Curr Neurol Neurosci Rep 6: 460-8 [PubMed: 17074280]

116. Balachandran A, Charlton K. 1994 Experimental rabies infection of non-nervous tissues in skunks (Mephitis mephitis) and foxes (Vulpes vulpes). Vet Pathol 31: 93-102 [PubMed: 8140732]

117. Lackay SN, Kuang Y, Fu ZF. 2008 Rabies in small animals. Vet Clin North Am Small Anim Pract 38: 851-61, ix [PubMed: 18501283]

118. Davis AD, Gordy PA, Bowen RA. 2013 Unique characteristics of bat rabies viruses in big brown bats (Eptesicus fuscus). Arch Virol 158: 809-20 [PubMed: 23208279]

119. Turmelle AS, Jackson FR, Green D, McCracken GF, Rupprecht CE. 2010 Host immunity to repeated rabies virus infection in big brown bats. J Gen Virol 91: 2360-6 [PubMed: 20519458]

120. Jackson AC. 2013 Current and future approaches to the therapy of human rabies. Antiviral Res 99: 61-7 [PubMed: 23369672]

121. Gilbert AT, Petersen BW, Recuenco S, Niezgoda M, Gomez J, Laguna-Torres VA, Rupprecht C. 2012 Evidence of rabies virus exposure among humans in the Peruvian Amazon. Am J Trop Med Hyg 87: 206-15 [PubMed: 22855749]

122. Davis AD, Jarvis JA, Pouliott C, Rudd RJ. 2013 Rabies virus infection in Eptesicus fuscus bats born in captivity (naive bats). PLoS One 8: e64808 [PubMed: 23741396] 

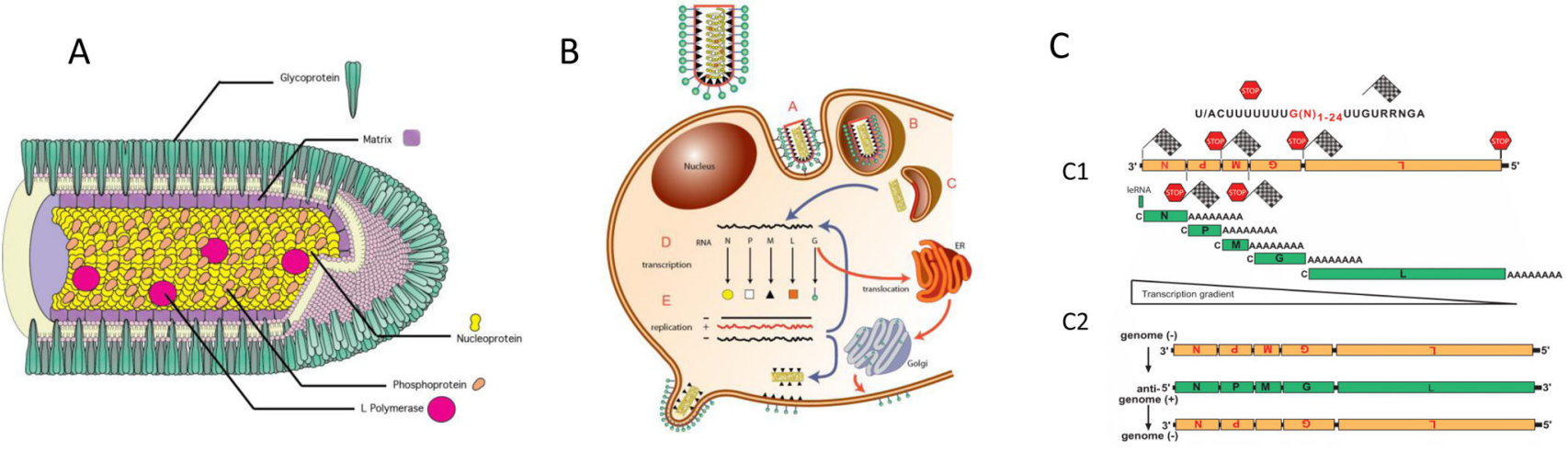

Figure 1:

The RABV transcription and replication strategy. The negative-sense genomic RNA (in orange) is the template for the L-P polymerase complex. A) During transcription, Five $5^{\prime}$ end capped (C) and polyadenylated (A) mRNAs (in green) encode the viral proteins. The polymerase complex disassociates from the template at each termination signal (STOP). The polymerase does not always re-engage successfully, leading to a negative transcription gradient from $3^{\prime}$ to $5^{\prime}$. B) During replication, the negative-sense genome is transcribed into a positive-sense antigenomic RNA intermediate (in green) by a more processive form of the viral polymerase. The anti-genome is then transcribed back into a negative-sense RNA to complete replication. 


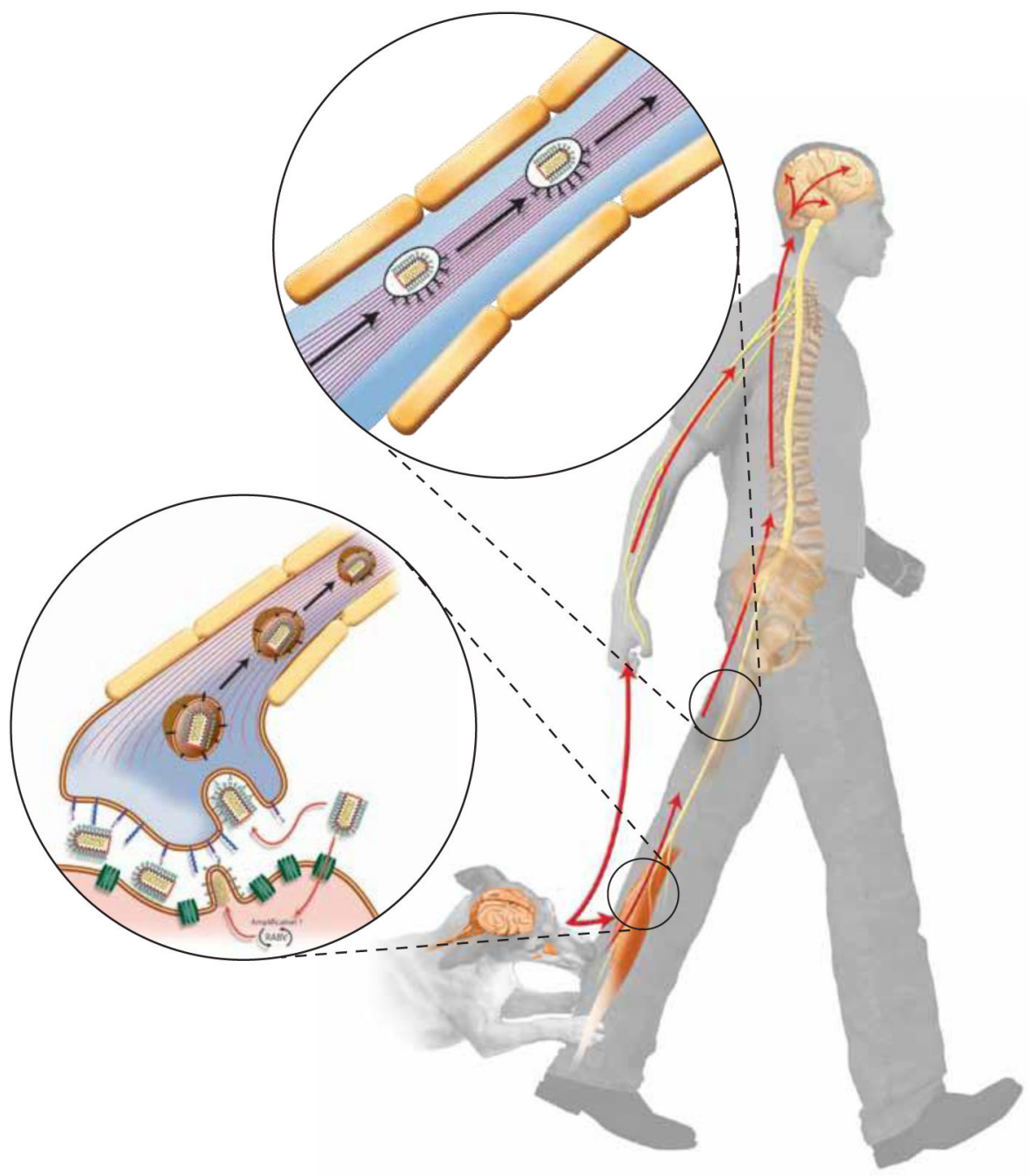

Figure 2:

The path of RABV infection through the host. Most natural RABV infections start with exposure of muscle tissue to RABV particles by an animal bite or scratch. The infection spreads to the peripheral nervous system through neuromuscular junctions (bottom insert). Virus particles travel as an enveloped vesicle using dynein-mediate retrograde axonal transport pathways (top insert), spreading trans-synaptically from post-synaptic to presynaptic neurons until widespread infection of the central nervous system is achieved. 


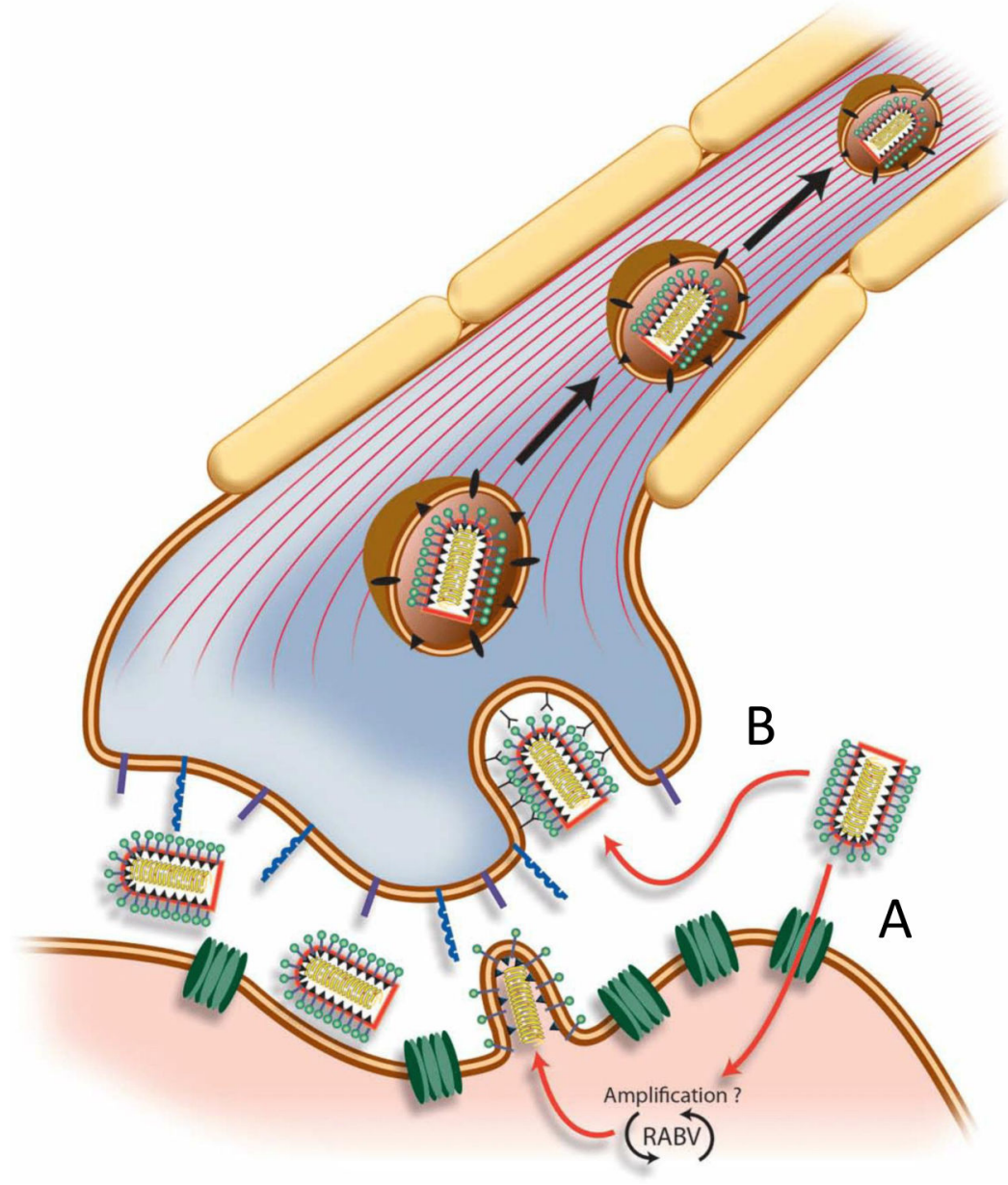

Figure 3:

The RABV neuroinvasive strategy. Two possible mechanisms are depicted, both of which have been observed experimentally. A) RABV-G interacts with the nicotinic acetylcholine receptor (nAcHR; in green), mediating entry into muscle cells. This leads to local replication of the virus before budding into the synaptic cleft of the neuromuscular junction. B) Alternatively, RABV-G interacts with one of several cellular receptors on the neuron, such as NCAM or p75NTR (shown in purple or blue). This leads to direct entry into the neuron without prior local replication in muscle. 